\title{
Characterization of Drawn and Undrawn Poly-L-Lactide Films by Differential Scanning Calorimetry
}

John F. Turner II

Cleveland State University, J.F.TURNER@csuohio.edu

A. Riga

Cleveland State University

Anne O'Connor

Cleveland State University, a.oconnor@csuohio.edu

Jing Zhang

Cleveland State University

Jennifer Collis

Cleveland State University

Follow this and additional works at: https://engagedscholarship.csuohio.edu/scichem_facpub

Part of the Chemistry Commons

How does access to this work benefit you? Let us know!

Publisher's Statement

The final publication is available at Springer via http://dx.doi.org/10.1023/

B:JTAN.0000017347.08469.b1

\section{Recommended Citation}

Turner, John F. Il; Riga, A.; O'Connor, Anne; Zhang, Jing; and Collis, Jennifer, "Characterization of Drawn and Undrawn Poly-L-Lactide Films by Differential Scanning Calorimetry" (2004). Chemistry Faculty Publications. 303.

https://engagedscholarship.csuohio.edu/scichem_facpub/303

This Article is brought to you for free and open access by the Chemistry Department at EngagedScholarship@CSU. It has been accepted for inclusion in Chemistry Faculty Publications by an authorized administrator of EngagedScholarship@CSU. For more information, please contact library.es@csuohio.edu. 


\title{
CHARACTERIZATION OF DRAWN AND UNDRAWN POLY-L-LACTIDE FILMS BY DIFFERENTIAL SCANNING CALORIMETRY
}

\author{
J. F. Turner II , A. Riga, A. O'Connor, J. Zhang and J. Collis
}

\begin{abstract}
Poly $L$ lactic acid (PLLA) is an optically active, biocompatible and biodegradable polymer that has been widely investigated as an artificial cell scaffold material. In its most crystalline form, PLLA is highly anisotropic and is one of the most piezoelectric polymers known. Conversely, amorphous PLLA exhibits little, if any, piezoelectric behavior. Compression molded PLLA films can be endowed with varying amounts of crystalline character and piezoelectricity by uniaxially stretching the polymer in a hot air bath. Understanding the precise crystalline architecture of PLLA that results from tensile drawing is important for constructing cell scaffolds that have highly tailored biodegradation and cell guiding properties. In our work here, we investigate the changes in the thermal properties of PLLA at draw ratios between 1.0 and 5.5 using differential scanning calorimetry (DSC). The crystallinity of the compression molded undrawn starting material is characterized using $\mathrm{X}$ ray diffraction. Our DSC re sults show an increase in percent crystallinity with increasing draw up to a draw ratio of 4.0. At greater draw ratios, there is a decrease in the crystalline character exhibited by PLLA.
\end{abstract}

Keywords: biomaterials, DSC, poly $L$ lactic acid

\section{Introduction}

The poly-( $\alpha$-hydroxy acids), poly-(lactide) and poly-(glycolides) are the most utilized of the commercially available biodegradable polymers. These biocompatible polymers are approved for use in human subjects by the FDA and have been employed as suture materials, tissue scaffolds and supports, and drug delivery devices. More recently, these materials have been used to construct three-dimensional architectures for the seeding of cells in specialized biomedical applications [1-4]. Optically active poly- $L$ lactide (PLLA) is the semi-crystalline form of poly-(lactide) having the general formula poly- $\left(\mathrm{O}-\mathrm{CO}-\mathrm{CH}\left(\mathrm{CH}_{3}\right)\right)_{\mathrm{n}}$. PLLA has been employed as a biodegradable bone implant material in both animals and humans [5-7], and has been used as an artificial scaffold for retinal pigment epithelium studies as well as other tissue regeneration studies 
[8-11]. The poly-(lactide) material has gained clinical attention in recent years as a likely candidate for use in the construction of artificial internal fixation devices. The biodegradability and mechanical stability of PLLA make it an attractive alternative to ceramic and metal implant materials that require surgical removal.

The physiological and mechanical properties of biopolymers are strongly influenced by composition, the degree of crystallinity, and polymer chain orientation. During metabolization in vivo, PLLA is degraded by hydrolytic de-esterification into lactic acid [6, 12-14]. The non-toxic lactic acid monomers are further metabolized in the carboxylic acid cycle where they are expelled by the lungs as water and carbon dioxide [13]. The morphology and crystallinity of PLLA strongly influence its rate of biodegradation $[15,16]$. By carefully adjusting the PLLA preparation parameters, it is possible to tailor its mechanical properties to suit a particular application [17, 18]. In biodegradable PLLA implants, for example, the rate of hydrolysis and polymer degradation in vivo slow with increasing crystallinity. Consequently, crystalline PLLA is better suited than amorphous PLLA in the construction of fixation devices that exhibit long-term mechanical and chemical stability, such as in orthopedic and dental implants. Amorphous PLLA, although it has less mechanical strength and poorer dimensional stability, is ideal for applications where simultaneous mass loss and molecular mass degradation are necessary $[17,19]$.

When PLLA is drawn at temperatures above its glass transition temperature and well below the melting temperature, its molecular orientation increases. While homogeneous sample crystallinity is sought, uniformly drawing the polymer into large sheets is difficult due to the formation of localized stresses in the material. The more highly drawn regions of the sample become more crystalline while the less drawn regions retain their more amorphous character [20]. Likewise, samples that are initially highly crystalline experience smaller changes in crystallinity during drawing. In the case of amorphous or semi-crystalline samples, the degree of induced crystallinity depends on the amorphous character initially present in the substrate [20]. Interestingly, drawn PLLA exhibits a strong shear piezoelectric response that has been implicated as an osteogenic enhancer in PLLA bone implants [21,22]. The piezoelectricity of drawn PLLA is a consequence of the long-range ordering of the chiral carbon atoms in the repeating units. Consequently, PLLA piezoelectricity should correlate well with sample crystallinity. For highly drawn samples, the crystallinity is diminished as fibrillization occurs, causing a decrease in the piezoelectric constant [23].

The objective of the work presented here is to understand the thermal-physical properties of PLLA. The induced changes in these properties as a function of draw ratio are determined using DSC. The aim of our work is to investigate the crystalline architecture of drawn PLLA as a prelude to further studies intended to investigate the role of piezoelectricity and crystalline architecture in the efficacy of artificial cell scaffold designs. In addition, it is well established that topographical features on the surface of scaffold materials can strongly influence cell orientation and alter cell proliferation [24]. Whether piezoelectricity, in the case of PLLA, or the topography resulting from specific crystalline architectures is more influential to the growth and proliferation of cells remains elusive. This work is the first step in our investigation to 
selectively modify the properties of PLLA to enhance its performance as a cell scaffold material.

\section{Experimental}

\section{Preparation of polymer plaques}

Poly- $L$-lactide pellets (Birmingham Polymers, Birmingham, AL) having a mass average molecular mass, $M_{\mathrm{w}}$, equal to 134.000 and a number average molecular mass, $M_{\mathrm{n}}$, equal to 83.900 were utilized for this work. The inherent viscosity, [ $\eta$, of the purchased PLLA pellets is $0.95 \mathrm{dL} \mathrm{g}{ }^{1}$ in $\mathrm{CHCl}_{3}$ at $30^{\circ} \mathrm{C}$. The PLLA pellets are first compression molded into plaques using a 12-ton manual hydraulic press (Carver) equipped with temperature controllers (Omega) to maintain the temperature of the plates at $195^{\circ} \mathrm{C}$. The PLLA pellets are then placed between Teflon coated foils in a $15.2 \mathrm{~cm}$ square frame having a thickness of $0.75 \mathrm{~mm}$. The frame is placed between the heated plates for $2 \mathrm{~min}$ prior to the application of pressure. The PLLA is then molded for $5 \mathrm{~min}$ under $9977 \mathrm{~kg}$ of pressure. After molding, the plaques are immediately quench cooled in dry ice to prevent further crystallization. The molded plaques are cut into standard dumbbell shapes measuring $6.35 \mathrm{~cm}$ long by $1.27 \mathrm{~cm}$ wide at the ends, with the narrowest part in the middle being $0.25 \mathrm{~cm}$ using a standard die (ASTM Type IV, Dewes-Gumbs Die Company). The samples are stored in a desiccator at $0^{\circ} \mathrm{C}$.

\section{X-ray diffraction}

X-ray diffraction (Phillips, Xpress) is performed on a sample of the compression-molded plaques in order to characterize the crystallinity of the pre-drawn PLLA. Figure 1 shows X-ray diffraction data of undrawn PLLA. The broad diffraction peak

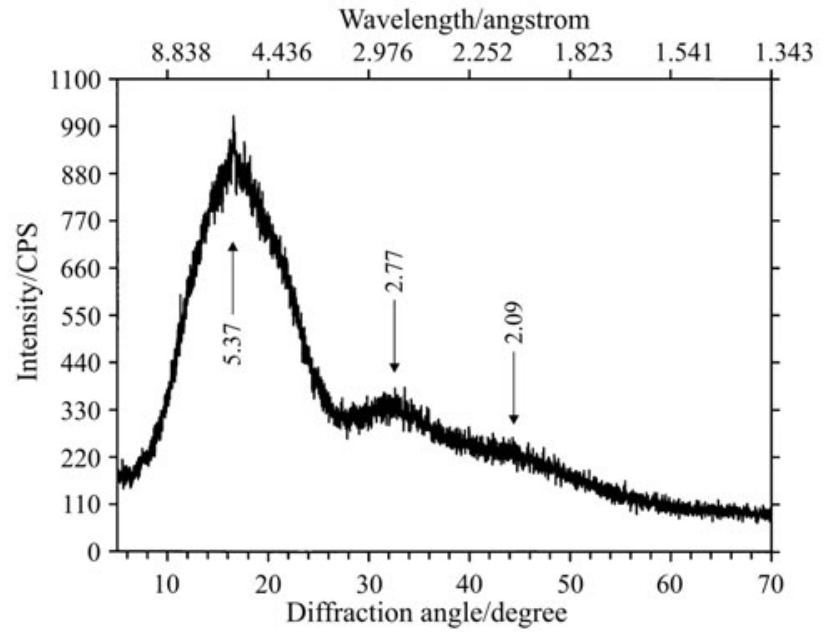

Fig. 1 X ray diffraction data of undrawn PLLA. The broad XRD peaks are indicative of small crystallites in the starting material. The estimated crystallite size is be tween 10 and $50 \mathrm{~nm}$ 
indicated small crystallite size and semi-crystalline character. The crystallite size ranges between $\sim 3 \mathrm{~nm}$ for undrawn PLLA and $\sim 100 \mathrm{~nm}$ for highly drawn PLLA as calculated from the Scherrer equation,

$$
L=\frac{K \lambda}{\beta_{0} \cos \theta}
$$

where $L$ is the crystallite dimension, $\beta_{0}$ is the breadth of the reflection corrected for instrument response, $\lambda$ is the diffraction wavelength, $\theta$ is the diffraction angle, and $K$ is approximately unity [25].

\section{Tensile drawing of PLLA}

A mechanical stretcher was constructed from a stepper motor (AMP, Size 23, 4023-819) and custom threaded rod (worm) assembly. An aluminum rod attached to a movable chuck on the worm passes through the insulated wall of a conventional laboratory oven (Cole Palmer 05015-58) and terminates in an adjustable clamp. One end of the polymer is clamped to the rod assembly and the other end is clamped to a fixed platform inside the oven. The stepper motor driver circuit is interfaced to the parallel port of a computer (Gateway, Pentium 4) using control software written in MFC/C++ (Microsoft Visual Studio 6.0). The software enables user control of the draw ratio and draw rate. The draw ratio, $D$, is defined as

$$
D=\frac{l_{\mathrm{f}}}{l_{\mathrm{i}}}
$$

where $l_{\mathrm{i}}$ and $l_{\mathrm{f}}$ are the initial (undrawn) and final (drawn) sample length. A draw rate of $\sim 0.1 \mathrm{~cm} \mathrm{~s}{ }^{1}$ was employed for the PLLA samples described here. The temperature while drawing is held at $(66 \pm 1)^{\circ} \mathrm{C}$. Higher temperatures cause the sample to become brittle and lead to frequent breakage of the sample before stretching is completed. The temperature was monitored using a multimeter (Fluke, 79III) and thermocouple (Fluke, 80TK). Samples were prepared with draw ratios of 1.0, 1.5, 2.0, 2.5, 3.0, 3.5, $4.0,4.5,5.0$ and 5.5.

\section{Differential scanning calorimetry}

The thermal properties of the undrawn and drawn PLLA were measured with a differential scanning calorimeter (TAI, model MTDSC 2920) calibrated with Indium, which melts at $156.7^{\circ} \mathrm{C}$ and has a heat of fusion equal to $28.4 \mathrm{~J} \mathrm{~g}{ }^{1}$. Pieces of drawn and undrawn PLLA samples weighing approximately $4 \mathrm{mg}$ were cut from the respective dogbone centers using a dry razor blade that had been heated to $65^{\circ} \mathrm{C}$ in a water bath to minimize cutting artifacts. Samples having draw ratios from 1.0 to 5.5 were investigated using heat-only modulated temperature differential scanning calorimetry (MTDSC) in a nitrogen atmosphere. The temperature program heated at a rate of $5^{\circ} \mathrm{C} \mathrm{min}{ }^{1}$ from 0 to $200^{\circ} \mathrm{C}$ and then automatically cooled back to $0^{\circ} \mathrm{C}$. The glass transition temperature, $T_{\mathrm{g}}$, crystallization temperature, $T_{\mathrm{c}}$, melting temperature, $T_{\mathrm{m}}$, 
heat of fusion, $\Delta H_{\mathrm{f}}$ and the heat of crystallization, $\Delta H_{\mathrm{c}}$, were determined for each sample from the curves. The measured values for $\Delta H_{\mathrm{c}}$ and $\Delta H_{\mathrm{f}}$ enable the determination of percent crystallinity as described in the results section.

In addition, samples having draw ratios of 1.0 (undrawn) and 5.0 (highly drawn) were investigated using conventional DSC at a heating rate of $10^{\circ} \mathrm{C} \mathrm{min}{ }^{1}$ for comparison. The effect of heating rate was investigated for additional undrawn samples using conventional DSC at heating/cooling rates of $5,10,20,30$ and $40^{\circ} \mathrm{C} \min ^{1}$.

\section{Results and discussion}

The glass transition temperature $\left(T_{\mathrm{g}}\right)$, crystallization temperature $\left(T_{\mathrm{c}}\right)$, melting temperature $\left(T_{\mathrm{m}}\right)$, crystallization enthalpy $\left(\Delta H_{\mathrm{c}}\right)$ and melting enthalpy $\left(\Delta H_{\mathrm{f}}\right)$ for each draw ratio are listed in Table 1. The advantage of MTDSC is that complex or subtle transitions may be analyzed independent of the baseline drift that is often associated with changes in the heat capacity observed in conventional DSC. In Fig. 2, the total heat flow, reversing heat flow (heat capacity component) and the non-reversing heat flow (kinetic component) are shown for undrawn PLLA. The presence of a postcrystallization peak is indicative of an increase in sample crystallinity that occurs during the melting process [26]. The endothermic deflection at the glass transition is likely due to the enthalpy stress-relaxation effect $[23,27]$. In Table 1 , it is apparent that the post-crystallization enthalpies and, to a lesser extent, the post-crystallization temperature tend to decrease with increasing draw ratio. The sample having a draw ratio of 2.0 is an exception $\left(\Delta H_{\mathrm{c}}=7.0 \mathrm{~J} \mathrm{~g}^{1}\right)$. The $\Delta H_{\mathrm{c}}$ values for draw ratios 1.0 and

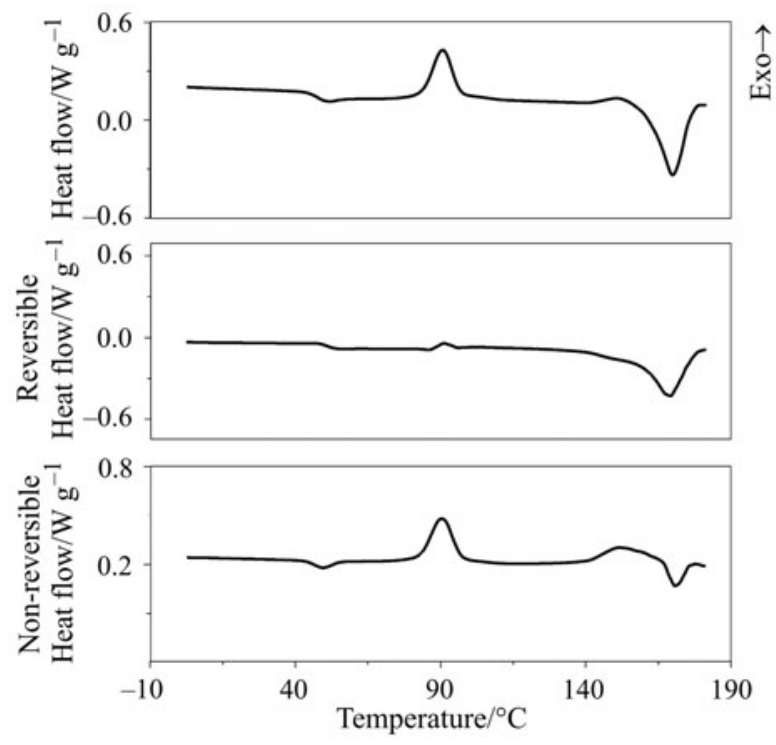

Fig. 2 Modulated temperature DSC (MTDSC) of undrawn PLLA (draw ratio 1.0). The heating rate is $5^{\circ} \mathrm{C} \mathrm{min}^{-1}$ in a nitrogen atmosphere 


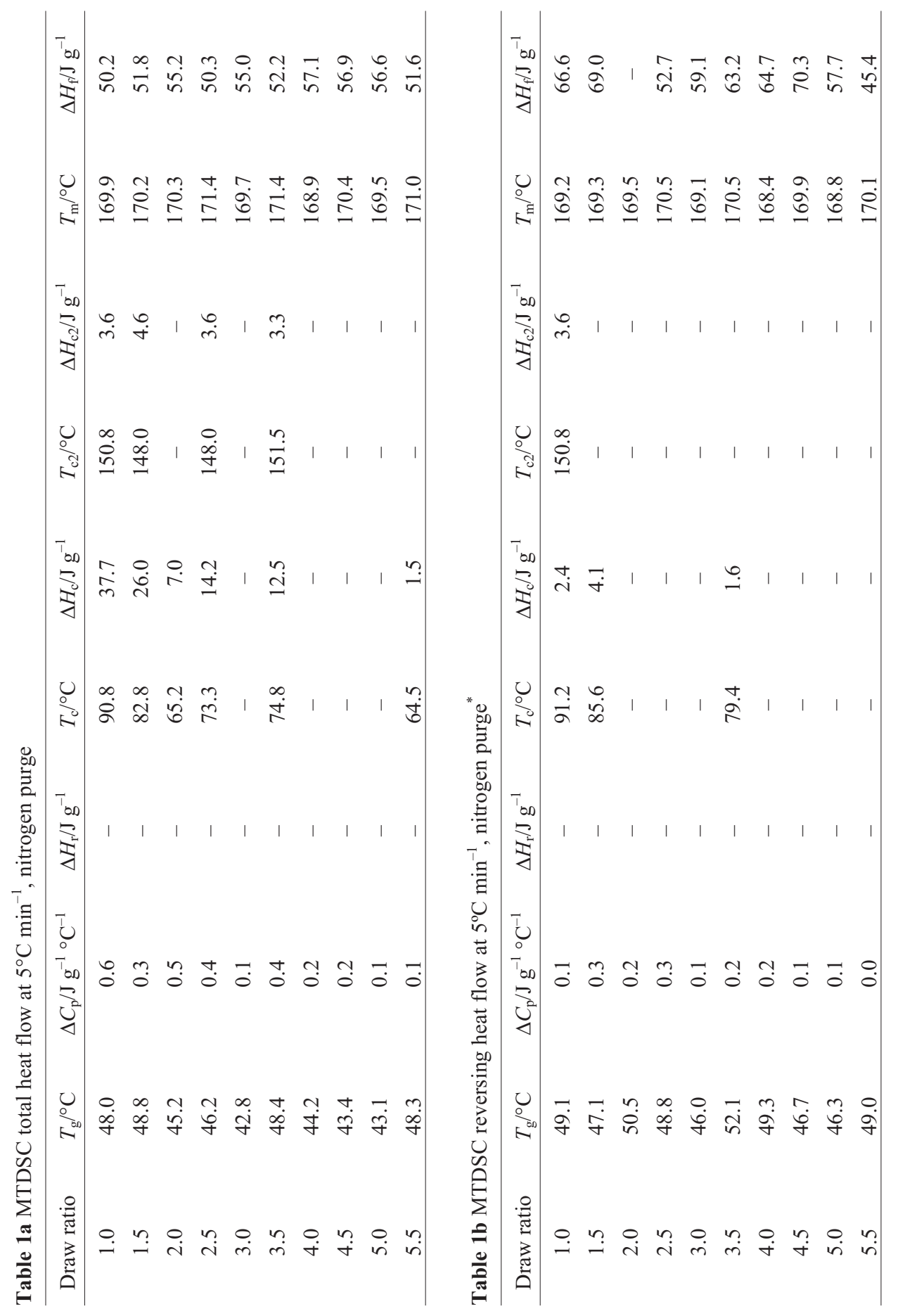




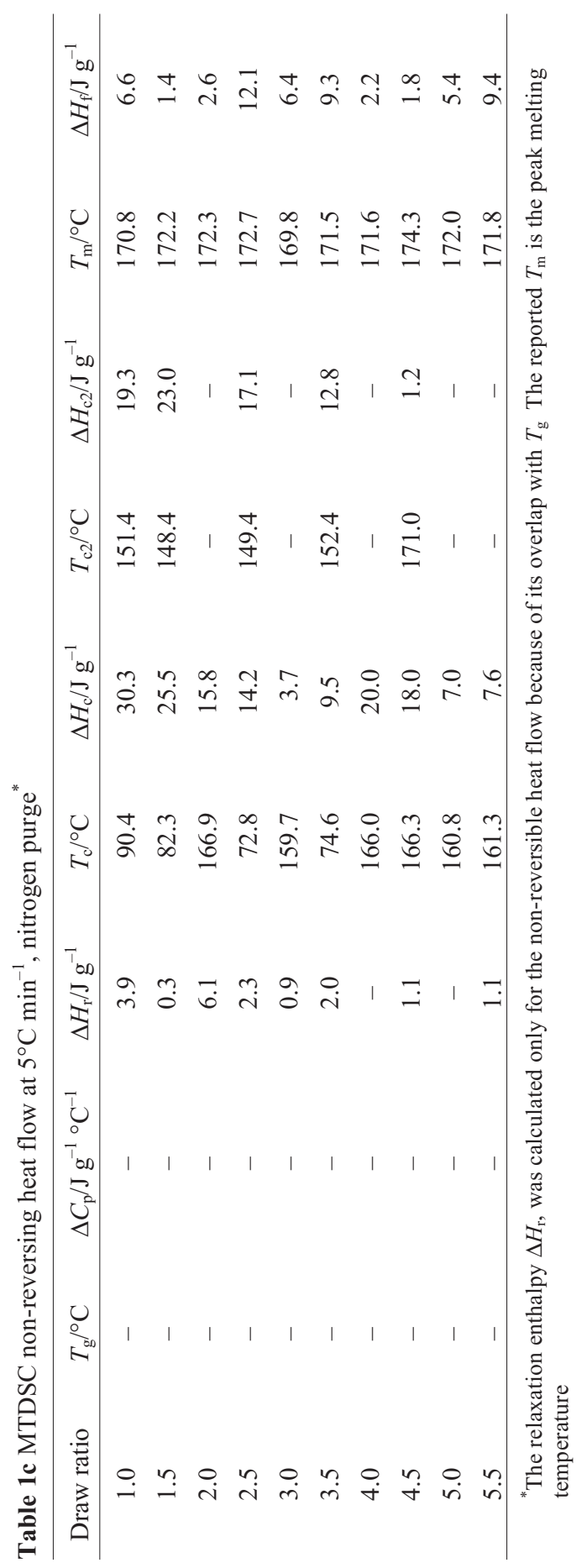


3.5 are 36.2 and $14.6 \mathrm{~J} \mathrm{~g}{ }^{1}$, respectively. The presence of a glass transition and postcrystallization exotherm reveal that the polymer contains amorphous regions and crystalline regions. At draw ratios between 4.0 and 5.0 there are no observed crystallization exotherms, which suggests that amorphous regions in the polymer have been transformed into more crystalline regions as a result of the mechanical drawing of the polymer. A small crystallization exotherm observed for the 5.5 draw ratio likely indicates overstretching of the polymer chains and a corresponding loss in crystallinity. Overall, the data suggests that the molecular chains tend to become more ordered during the drawing process. The greater mechanical stability and tensile strength of the polymer reported in the literature concur with the increased ordering of the polymer.

The conventional DSC curves in Fig. 3 were acquired using a heating rate of $10^{\circ} \mathrm{C} \mathrm{min}{ }^{1}$ on samples having draw ratios of 1.0 and 5.0. Again, it is observed that the post-crystallization temperature, $T_{\mathrm{c}}$, and post-crystallization enthalpy, $\Delta H_{\mathrm{c}}$, decrease with increasing draw ratio (Table 2). The onset of a smaller, second exotherm is observed between 139 and $148^{\circ} \mathrm{C}$ in the conventional DSC data, and is near the melting temperature. This is due to additional crystallization in the melting region of the polymer. MTDSC reveals an underlying exothermic crystallization process that is superimposed on the melt endotherm of the heat flow $v s$. temperature curve. The non-reversing phase of the MTDSC (Fig. 2) clearly delineates an exothermic crystallization from 137 to $148^{\circ} \mathrm{C}$. The reversing phase shows the melting as $156^{\circ} \mathrm{C}$ (extrapolated onset temperature) to $169^{\circ} \mathrm{C}$ (peak temperature). Therefore, there are two or more crystallization events occurring during heating of the PLLA. A closer look at the total heat flow curve for the apparent melting endotherm reveals that the net endotherm is composed of an exotherm (second crystallization) and the endotherm for melting. In order to fully understand the crystallinity of PLLA one must scrutinize the observed melt endotherm by MTDSC.

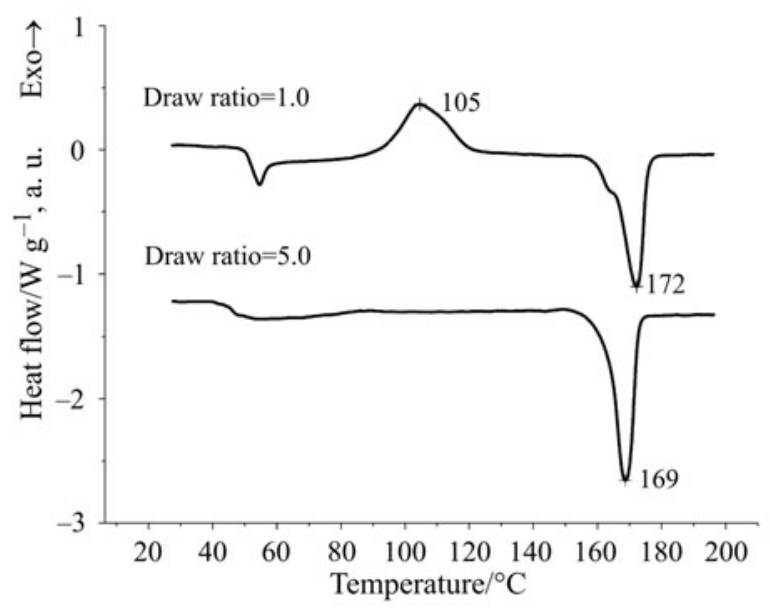

Fig. 3 The effect of PLLA draw ratio by DSC 
Table 2a Amorphous character*

\begin{tabular}{ccc}
\hline Draw ratio & $T_{\mathrm{g}} /{ }^{\circ} \mathrm{C}$ & $\Delta C_{\mathrm{p}} / \mathrm{J} \mathrm{g}^{-1}{ }^{\circ} \mathrm{C}^{-1}$ \\
\hline 1.0 & 52.8 & 1.6 \\
5.0 & 46.1 & 0.8 \\
\hline
\end{tabular}

Table 2b Crystalline character*

\begin{tabular}{crccccc}
\hline Draw ratio & $T_{\mathrm{c}}{ }^{\circ} \mathrm{C}$ & $\Delta H_{\mathrm{c}} / \mathrm{J} \mathrm{g}^{-1}$ & $T_{\mathrm{c} 2} /{ }^{\circ} \mathrm{C}$ & $\Delta H_{\mathrm{c} 2} / \mathrm{J} \mathrm{g}^{-1}$ & $T_{\mathrm{m}} /{ }^{\circ} \mathrm{C}$ & $\Delta H_{\mathrm{f}} / \mathrm{J} \mathrm{g}^{-1}$ \\
\hline 1.0 & 104.5 & 48.0 & & & 172.1 & 53.4 \\
5.0 & 85.6 & 5.0 & 149.9 & 2.2 & 168.7 & 55.4 \\
\hline
\end{tabular}

${ }^{*}$ Conventional DSC data acquired at $10^{\circ} \mathrm{C}$ min ${ }^{1}$ using a nitrogen purge.

Ideally, we are most interested in the crystallinity of PLLA at $37^{\circ} \mathrm{C}$, the temperature at which PLLA is utilized in vivo for biological applications such as drug delivery devices or artificial scaffolds for cell generation. In order to understand the effect of heating rate on the PLLA curves and to identify an appropriate heating rate upon which to base our determination of percent crystallinity, we investigated undrawn samples at heating rates between 10 and $50^{\circ} \mathrm{C} \mathrm{min}{ }^{1}$ using conventional DSC (Fig. 4). The glass transition temperatures, crystallization temperatures, and peak widths in-

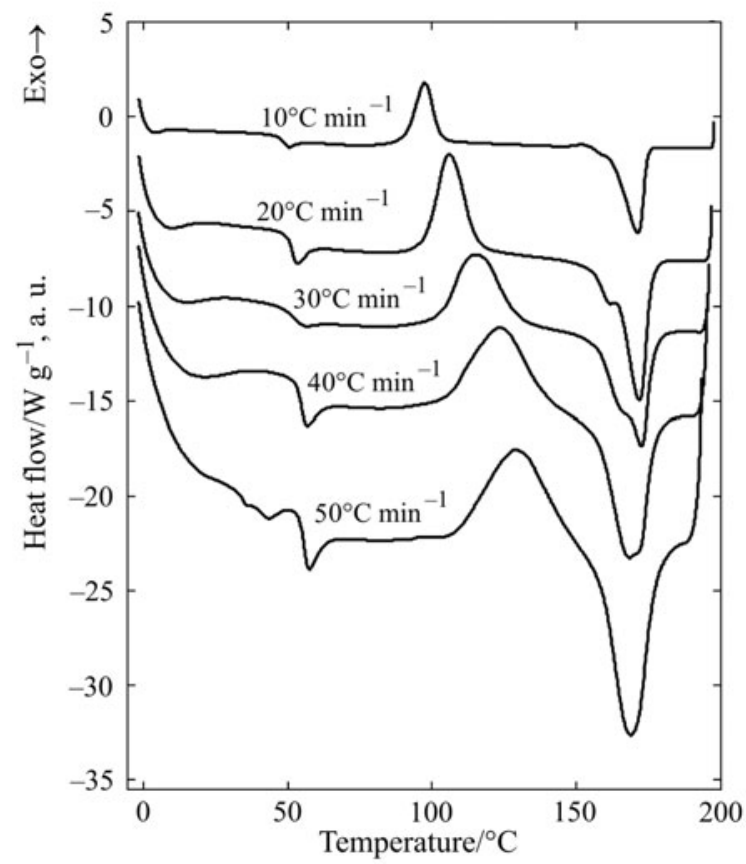

Fig. 4 The effect of DSC heating rates. The DSC curves were acquired on undrawn samples (draw ratio 1.0) in a nitrogen purge 
crease with increasing heating rates (Table 3). At heating rates above $20^{\circ} \mathrm{C} \min { }^{1}$, however, it becomes increasingly difficult to determine the temperature where melting begins. At the higher heating rates, an exotherm is observed at the glass transition in addition to the stress relaxation endotherm. While the $10^{\circ} \mathrm{C}$ min ${ }^{1}$ curve appears sufficiently free of heating rate artifacts, the percent crystallinity is determined at a conservative $5^{\circ} \mathrm{C}$ min ${ }^{1}$ using MTDSC.

Table 3 The effect of DSC heating rate for undrawn samples

\begin{tabular}{ccccccc}
\hline $\begin{array}{c}\text { Heating rate/ } \\
{ }^{\circ} \mathrm{C} \mathrm{min}^{-1}\end{array}$ & $\begin{array}{c}T_{\mathrm{g} /} / \\
{ }^{\circ} \mathrm{C}\end{array}$ & $\begin{array}{c}T_{\mathrm{c}} / \\
{ }^{\circ} \mathrm{C}\end{array}$ & $\begin{array}{l}\Delta H_{\mathrm{c}} / \\
\mathrm{J} \mathrm{g}^{-1}\end{array}$ & $\begin{array}{c}T_{\mathrm{m}} / \\
{ }^{\circ} \mathrm{C}\end{array}$ & $\begin{array}{c}\Delta H_{\mathrm{f}} / \\
\mathrm{J} \mathrm{g}^{-1}\end{array}$ & $\begin{array}{c}\chi_{\mathrm{c}} / \\
\%\end{array}$ \\
\hline 10 & 47.8 & 97.5 & 36.0 & 171.2 & 47.3 & 12.1 \\
20 & 51.8 & 105.8 & 38.9 & 171.7 & 50.5 & 12.4 \\
30 & 52.8 & 115.5 & 40.5 & 172.4 & 46.0 & 5.9 \\
40 & 54.9 & 123.6 & 38.5 & 168.1 & 47.5 & 9.6 \\
50 & 55.7 & 129.1 & 32.7 & 168.7 & 42.8 & 10.8 \\
\hline
\end{tabular}

A comparison of the values for percent crystallinity as a function of draw ratio is shown in Fig. 5. As the draw ratio increases, the percent crystallinity increases up to a draw ratio of $\sim 4.0$. At very high draw ratios the polymer begins to exhibit less crystallinity. The percent crystallinity values for each draw ratio are listed in Table 4. One conventional calculation of percent crystallinity, $\chi_{c}$, determines the total amount of crystalline character that develops in the sample at temperatures below the melting temperature and is calculated as

$$
\chi_{\mathrm{c}}=10\left(\frac{\Delta H_{\mathrm{f}}}{93.6}\right),
$$

where $93.6 \mathrm{~J} \mathrm{~g}^{1}$ is the reported $\Delta H_{\mathrm{f}}$ for a $100 \%$ crystalline PLLA sample [22].

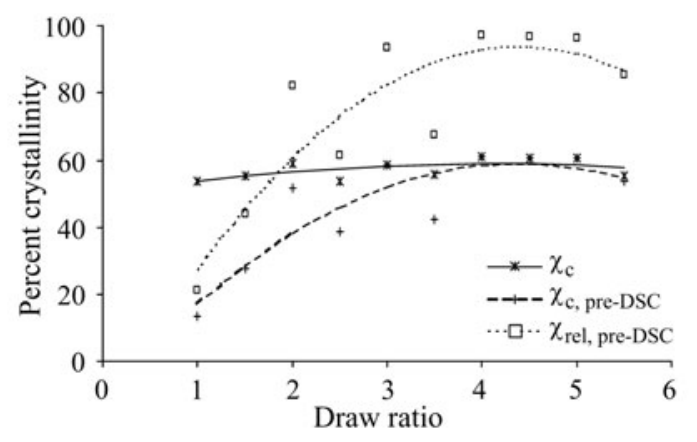

Fig. 5 The percent crystallinity of PLLA plotted as a function of draw ratio 
Table 4 Percent crystallinity

\begin{tabular}{cccc}
\hline Draw ratio & $\chi_{c}$ & $\chi_{c, \text { pre-DSC }}$ & $\chi_{\text {rel, pre-DSC }}$ \\
\hline 1.0 & 53.6 & 13.4 & 21.9 \\
1.5 & 55.3 & 27.6 & 45.2 \\
2.0 & 59.0 & 51.5 & 84.4 \\
2.5 & 53.7 & 38.6 & 63.2 \\
3.0 & 58.8 & 58.8 & 96.3 \\
3.5 & 55.8 & 42.4 & 69.5 \\
4.0 & 61.0 & 61.0 & 100.0 \\
4.5 & 60.8 & 60.8 & 99.6 \\
5.0 & 60.5 & 60.5 & 99.1 \\
5.5 & 55.1 & 53.5 & 87.7 \\
\hline
\end{tabular}

In our work, however, we are interested in the crystalline content of the drawn and undrawn PLLA as it exists immediately after sample preparation, just prior to its incorporation as an artificial cell scaffold material. To better understand the degree of crystalline character present in the PLLA samples at these conditions, we subtract $\Delta H_{\mathrm{c}}$ from $\Delta H_{\mathrm{f}}$ in the calculation of the pre-DSC percent crystallinity, $\chi_{\mathrm{c}, \text { pre-DSC, }}$ according to:

$$
\chi_{\mathrm{c}, \text { pre-DSC}}=100\left(\frac{\Delta H_{\mathrm{f}}-\Delta H_{\mathrm{c}}}{93.6}\right) \text {. }
$$

Although $93.6 \mathrm{~J} \mathrm{~g}{ }^{1}$ is the reported $\Delta H_{\mathrm{f}}$ for a $100 \%$ crystalline sample [28], our most crystalline drawn sample yields $58.7 \mathrm{~J} \mathrm{~g}^{1}$ during melting and exhibits no post-crystallization peak. In order to make relative comparisons between newly drawn samples and our most crystalline sample, it is convenient to calculate

$$
\chi_{\text {rel }}=100\left(\frac{\Delta H_{\mathrm{f}}-\Delta H_{\mathrm{c}}}{58.7}\right)
$$

where our empirical value of $58.7 \mathrm{~J} \mathrm{~g}^{1}$ is used in place of the literature value of $93.6 \mathrm{~J} \mathrm{~g}{ }^{1}$.

The result is a relative measure of percent crystallinity based on our most crystalline drawn sample and serves as a figure of merit for the crystallinity of drawn PLLA substrates.

\section{Conclusions}

DSC and MTDSC are suitable techniques for determination of relative crystallinity in PLLA-based biomaterial devices. We demonstrate that the crystallinity of drawn PLLA increases with draw ratio for draw ratios below 4.0. At larger draw ratios, the crystallinity begins to decrease as determined by MTDSC. In order to estimate the crystalline content of PLLA substrates used in biomedical applications at physiologically relevant temperatures, the percent crystallinity calculation must account for the 
formation of additional crystalline character that is formed in the sample during the DSC experiment at temperatures that exceed physiological temperatures.

$$
* * *
$$

The authors extend special thanks to undergraduate students Jennifer Seegichetla and Patrick Odea, Department of Chemistry, Cleveland State University for their help with data acquisition.

\section{References}

1 H. Tsuji, Biomaterials, 24 (2003) 537.

2 D. W. Grijpma, H. Altpeter, M. J. Bevis and J. Feijen, Polymer International, 51 (2002) 845.

3 J. Rak, J. L. Ford, C. Rostron and V. Walters, Pharm. Acta Helv., 60 (1985) 162.

4 H. Tsuji, Polymer, 43 (2002) 1789.

5 A. S. P. Lin, T. H. Barrows, S. H. Cartmell and R. E. Guldberg, Biomaterials, 24 (2003) 481.

6 M. A. Slivka, C. C. Chu and I. A. Adisaputro, J. Biomed. Mater. Res., 36 (1997) 469.

7 M. Borden, M. Attawia and C. T. Laurencin, J. Biomed. Mater. Res., 61 (2002) 421.

8 G. G. Giordano, T. C. Thomson, S. L. Ishaug, A. G. Mikos, S. Cumber, C. A. Garcia and D. Lahiri Munir, J. Biomed. Mater. Res., 34 (1997) 87.

9 R. Langer and J. P. Vacanti, Science, 260 (1993) 920.

10 T. Hadlock, S. Singh, J. P. Vacanti and B. J. McLaughlin, Tissue Engineering, 5 (1999) 187.

11 C. Chen, J. Chueh, H. Tseng, H. Huang and S. Lee, Biomaterials, 24 (2003) 1167.

12 J. Y. Lim, S. H. Kim, S. Lim and Y. H. Kim, Macromol. Mater. Eng., 288 (2003) 50.

13 P. Mäkelä, T. Pohjonen, P. Törmälä, T. Waris and N. Ashammakhi, Biomaterials, 23 (2002) 2587.

14 A. Majola, Annales Chirurgiae et Gynaecologiae, 80 (1991) 274.

15 H. Tsuji and A. D. Carpio, Biomacromolecules, 4 (2003) 7.

16 Y. Ikada, K. Jamshidi, H. Tsuji and S. H. Hyon, Macromolecules, 20 (1987) 904.

17 J. K. Lee, K. H. Lee and B. S. Jin, Eur. Pol. J., 37 (2001) 907.

18 Y. Maeda, J. Therm. Anal. Cal., 70 (2002) 669.

19 D. Cohn, H. Younes and G. Marom, Polymer, 28 (1987) 2018.

20 F. W. Billmeyer, Jr., Textbook of Polymer Science, John Wiley and Sons, New York 1984, p. 482.

21 T. Ochiai and E. Fukada, Jpn. J. Appl. Phys., 37 (1998) 3374.

22 E. Fukada, Biorheology, 32 (1995) 593.

23 Y. Ikada, Y. Shikinami, Y. Hara, M. Tagawa and E. Fukada, J. Biomed. Mat. Res., 30 (1996) 553.

24 W. J. Landis, Connect. Tissue Res., 34 (1996) 239.

25 L. E. Alexander, X ray Diffraction Methods in Polymer Science, Wiley, New York 1969, p. 335.

26 Gombás, P. Szabó Révész, M. Kata, G. Regdon Jr. and I. Erős, J. Therm. Anal. Cal., 68 (2002) 503.

27 D. Cam, S. Hyon and Y. Ikada, Biomaterials, 16 (1995) 833.

28 E. W. Fischer, H. J. Sterzel and G. Wegner, Kolloid Z. u. Z. Polymers, 251 (1973) 980. 